\title{
Serum Sodium Levels in Hospitalized Children with Community- Acquired Pneumonia: A Hospital-Based Case-Control Study Amira Mohamed Hamed ${ }^{1}$, Mohamed Fahmey Ibrahim ${ }^{1}$,*Hamada Kawshty Fayed ${ }^{2}$, Mona Mohamed Abd EL-Meguid ${ }^{3}$, Shimaa Esmail Hassen ${ }^{1}$ \\ Departments of ${ }^{1}$ Pediatrics and Neonatology, ${ }^{2}$ Chest Diseases, and \\ ${ }^{3}$ Clinical Pathology Faculty of Medicine, Al-Azhar University, Assiut, Egypt
}

Corresponding author: Hamada Kawshty Fayed, Phone number: +2 01093326825, E-mail: kawshtey1978@yahoo.com

\begin{abstract}
Background: community-acquired Pneumonia (CAP) is one of the frequent causes of hospital admission, whereas hyponatremia is a common electrolyte abnormality in hospitalized patients and associated with considerable morbidity and mortality.

Aim of the study: purpose of this study was to evaluate serum levels of sodium in children with CAP.

Patients and Methods: a total of 200 children included in the study were classified into two groups as follow: Group (I) Cases group: Included 100 child with clinical and laboratory evidence of pneumonia ranging from one month to three years and Group (II) Control group: Includes 100 child apparently healthy control who attended for non chest problem or serious medical condition. Serum sodium levels, hemoglobin levels, platelet count, total leucocyte count, and C-reactive protein were done to all children.

Results: Hyponatremia was present in $82 \%$ of patients with CAP (82 out of 100). Serum level of sodium was significantly lower in children with pneumonia than healthy control $(132.08 \pm 4.18$ vs $139.42 \pm 2.57)$. There was a statistically significant negative correlation between the grade of respiratory distress and the level of serum sodium $(\mathrm{p}<0.001)$.

Conclusion: hyponatremia is common among hospitalized children with CAP. Serum sodium levels are lower in children with pneumonia than matched healthy controls.
\end{abstract}

Keywords: pneumonia, children, serum sodium

\section{INTRODUCTION}

Community-acquired pneumonia (CAP) is a common and potentially serious illness with considerable morbidity ${ }^{(1)}$. It is a major cause of morbidity and mortality in children less than five years old. Pneumonia is a vital reason of morbidity in the developed world, and also important cause of morbidity and mortality inside the growing global ${ }^{(2)}$.

Sodium is one of the most vital electrolytes within the body and is responsible for a number of crucial functions, mostly associated withregulation of fluid and water. Sodium is the abundant cation of the extracellular fluid. Levels of serum sodium change in patients with pulmonary infections. The normally accepted range for sodium is 134 to 145 $\mathrm{mEq} / \mathrm{L}^{(3)}$.

Hyponatremia ( $\mathrm{HN}$, serum sodium $<135$ $\mathrm{mEq} / \mathrm{L}$ ) is the most common electrolyte imbalance seen in clinical practice, and also in critically ill children. It is usually present in 3\% of hospitalized patients. Hyponatremia can be classified into three groups as mild (131-135 mmol/L), moderate $(126-130 \mathrm{mmol} / \mathrm{L})$, and severe $(\leq 125 \mathrm{mmol} / \mathrm{L})$. Mild to moderate $\mathrm{HN}$ and severe hyponatremia are found in $15-30 \%$ and $1-4 \%$, respectively of hospitalized patients ${ }^{(4)}$. The main cause of hyponatremia is volume depletion (bleeding, vomiting, diarrhea, and urinary loss), syndrome of irrelevant antidiuretic hormone (SIADH) secretion, congestive heart failure, thiazide diuretics, cirrhosis, renal failure, primary polydipsia, adrenal insufficiency, and hypothyroidism. Several lung disorders, including pneumonia, can cause SIADH through unknown mechanisms ${ }^{(5)}$.

Biochemical markers have been investigated in association with clinical outcome in patients with CAP, including multiple cytokines such as tumor necrosis factor- $\alpha$ and interleukin 6 (IL-6), C-reactive protein (CRP), procalcitonin, and D-dimer. The role of cytokines as essential mediatorsof lung defense towards infections and inflammation is well documented. Cytokines may have either pro- or anti-inflammatory impact depending on several interacting microbiologic, environmental, and genetic elements that are believed to influence host response to respiratory infections ${ }^{(\boldsymbol{6})}$.

Aim of this work is to evaluate serum sodium levels in patients who were admitted to the hospital with community-acquired pneumonia.

\section{PATIENTS AND METHODS}

This is a case-control study which was conducted during the period from December 2016 to November 2018. The total number of the study sample was 200 children aging (1 month to 3 years). The total number of children (200) included in the study were classified into two 
groups as follow: Group (I) Cases group: Included 100 children with clinical and laboratory evidence of pneumonia attending Pediatric department; Group (II) Control group: Included 100 children how were apparently healthy control who attended for non-chest problem or serious medical condition.

All included children were chosen according to the following:

Inclusion criteria: (1) Age from one month to three years; (2) Absence of significant illness; and (3) Confirmation of the clinical diagnosis of pneumonia by a chest $\mathrm{x}$-ray.

Exclusion criteria: (1) Neonate $(<$ four weeks of age) and children more than three years of age; (2) Children with bronchiolitis; (3) Children with a pre-existing lung disease, particularly asthma, tuberculosis \& bronchiectasis;

(4) Children with a congenital heart disease, or a chronic liver or kidney disease; (5) Postoperative children; (6) Children who had been hospitalized and treated for two or more days before inclusion in the study.

\section{Clinical methods:}

All cases were subjected to a complete clinical study (through history and physical examination) upon study inclusion, with concentration on symptoms and signs of pneumonia.

- History: careful history taking include demographic and epidemiological data e.g. age, residence, sex and smoking by any member in the family.

- Symptoms: fever, cough, dyspnea and sputum production, although non-respiratory symptoms such as consciousness alterations, falls, or gastrointestinal symptoms.

- Signs: tachypnea, nasal flaring, intercostal retraction, grunting, and cyanosis.

\section{Laboratory methods:}

The following investigations were performed: Complete blood counts (CBC); Quantitative Creactive protein (CRP) and Serum sodium level (Na).

\section{Blood sampling procedure:}

Four ml of venous blood were obtained from each patient by a sterile venipuncture and divided as follow: One $\mathrm{ml}$ of venous blood was added to a tube containing EDTA as anticoagulant for performing CBC. One $\mathrm{ml}$ of blood was added to the empty tube for performing a CRP test. Two $\mathrm{ml}$ of venous blood allowed clotting for $10-20$ minutes before centrifugation for 20 minutes at 2000-3000r.p.m remove supernatant to obtain serum.

\section{$A$ - CBC assessment:}

It was done by using auto hematology analyzer DIAGON Ltd (D-Cell 60).

\section{B- Serum sodium assessment:}

It was done by using electrolyte analyzer SENSA CORE. The normal blood sodium level is $135-145 \mathrm{mEq} / \mathrm{L}$ or $135-145 \mathrm{mmol} / \mathrm{L}$ in the international unit.

\section{C- Quantitative C-reactive protein (CRP):}

It was done by latex agglutination.

\section{Ethical statement:}

The study was approved by the local Ethical Committee of Al-Azhar University, to evaluate and publish information. Written consent was taken from parents or local guardian.

\section{Statistical methods}

Data entry and all statistical analyses were performed using Statistical Package for Social Science (SPSS) version 21 under Windows 7 operating system. Results are expressed as means \pm SD for quantitative data and by number $(\%)$ for qualitative data. Comparisons between the groups were conducted by independent sample t-test for parametric data and by Mann Whitney test for non-parametric data. Chi-Square test was used to test the significance between groups regarding qualitative data and Fisher exact test was used instead of the Chi-square test when the expected count in any cell found less than 5 .

ROC curve of sodium (receiver operating characteristic) was constructed.

The true positive rate (Sensitivity) is planned in perform the false positive rate (100Specificity) for various cut-off points. Each point on the ROC curve represents a sensitivity/specificity pair corresponding to a particular decision threshold. The area under the ROC curve (AUC) is a measure of how well a parameter will distinguish between two diagnostic teams (diseased/normal).

Probability level (P-value) was assumed as: $\mathrm{P}>0.05$ : Non significant (NS); $\mathrm{P}<0.05$ : Significant $(\mathrm{S})$ and $\mathrm{P}<0.01$ : Highly significant (HS).

\section{RESULTS}

The study population consisted of 200 children, classified into two groups; cases and control group. Each group consisted of 100 children. There was a statistically significant difference between two groups as regard to residence $(\mathrm{p}<0.005)$ but there was no statistically 
Amira Hamed et al.

significant difference as regard to age and sex (Table 1).

The majority of cases group was presented by cough (76 out of 100,76\%), expectoration (60 out of $100,60 \%$ ) and respiratory distress (100 out of $1000,100 \%)$. As regards clinical examination, there was a statistically significant increase in case group in comparison to control group in heart rate, respiratory rate and temperature $(\mathrm{p}<0.001)$, but there was no statistically significant difference regarding weight ( $\mathrm{p}<0.137$ ) (Table 2 and 3 ).

Laboratory data in both groups including hemoglobin, total leucocyte count and $\mathrm{C}$ reactive protein was presented in table (4) with a statistically significant difference between two groups.

Hyponatremia $(\mathrm{HN})$ (serum sodium $<135$ $\mathrm{mmol} / \mathrm{l})$ was present in $82 / 100(82 \%)$ patients with
CAP (case group); 50 patients had mild HN, 22 patients had moderate $\mathrm{HN}<130 \mathrm{mmol} / \mathrm{l}$, and 10 patients had severe $\mathrm{HN}<125 \mathrm{mmol} / \mathrm{l}$ (figure 1). The mean of serum sodium concentration \pm SD in case group $(132.08 \pm 4.18 \mathrm{mmol} / \mathrm{l})$ and was statistically significant lower than that in control group $(139.42 \pm 2.57 \mathrm{mmol} / \mathrm{l})(\mathrm{p}<0.001)($ Table 5$)$. There was a statistically significant negative correlation between the grade of respiratory distress and the mean value of serum sodium ( $\mathrm{p}$ $<0.001$ ) (Table 6).

Cut off value, AUC, sensitivity, specificity, positive predictive value (PPV), and negative predictive value (NPV) of serum sodium of cases versus controls was demonstrated in the table (7). ROC curve of sodium was illustrated in figure (2).

Table (1): Demographic data of studied groups

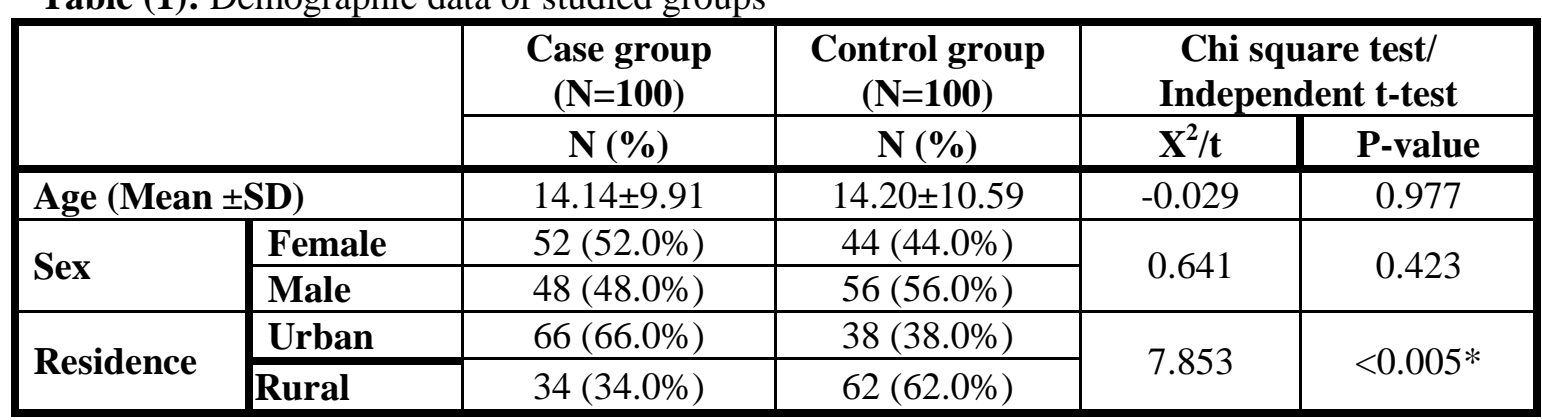

$\mathrm{N}$ : number, SD: standard deviation, *: P-value is statistically significant

Table (2): Clinical data of studied groups

\begin{tabular}{|c|c|c|c|c|c|}
\hline & & $\begin{array}{c}\text { Case group } \\
(\mathrm{N}=100)\end{array}$ & $\begin{array}{c}\text { Control group } \\
(\mathbf{N}=100)\end{array}$ & \multicolumn{2}{|c|}{ Chi square test } \\
\hline & & $\mathbf{N}(\%)$ & $\mathrm{N}(\%)$ & $\mathbf{X}^{2}$ & P-value \\
\hline \multicolumn{2}{|l|}{ Cough } & $76(76.0 \%)$ & $0(0.0 \%)$ & 61.290 & $<0.001 * *$ \\
\hline \multicolumn{2}{|l|}{ Sputum } & $60(60.0 \%)$ & $0(0.0 \%)$ & 42.857 & $<0.001 * *$ \\
\hline \multirow{5}{*}{ Respiratory distress } & I & $22(22.0 \%)$ & $0(0.0 \%)$ & \multirow{5}{*}{100.000} & \multirow{5}{*}{$<0.001 * *$} \\
\hline & II & $52(52.0 \%)$ & $0(0.0 \%)$ & & \\
\hline & III & $16(16.0 \%)$ & $0(0.0 \%)$ & & \\
\hline & IV & $10(10.0 \%)$ & $0(0.0 \%)$ & & \\
\hline & no RD & $0(0.0 \%)$ & $100(100.0 \%)$ & & \\
\hline
\end{tabular}

N: number; RD: respiratory distress, **: P-value is statistically highly significant

Table (3): Clinical examination of studied groups

\begin{tabular}{|c|c|c|l|c|}
\hline & $\begin{array}{c}\text { Case group } \\
(\mathbf{N}=100)\end{array}$ & $\begin{array}{c}\text { Control group } \\
(\mathbf{N = 1 0 0})\end{array}$ & \multicolumn{2}{|c|}{ Independent t-test } \\
\cline { 2 - 5 } & Mean \pm SD & Mean \pm SD & t & P-value \\
\hline HR & $144.76 \pm 6.02$ & $102.36 \pm 14.98$ & 18.571 & $<0.001^{* *}$ \\
\hline RR & $55.24 \pm 6.10$ & $29.76 \pm 3.30$ & 25.982 & $<0.001^{* *}$ \\
\hline Temp & $38.39 \pm 0.40$ & $37.22 \pm 0.17$ & 19.115 & $<0.001^{* *}$ \\
\hline Weight & $8.81 \pm 2.36$ & $9.61 \pm 2.95$ & -1.498 & 0.137 \\
\hline
\end{tabular}

HR: heart rate, RR: Respiratory rate, N: number, SD: standard deviation, **: P-value is statistically highly significant 
Table (4): Laboratory data of studied groups

\begin{tabular}{|c|c|c|c|c|}
\hline \multirow{2}{*}{} & $\begin{array}{c}\text { Case group } \\
(\mathbf{N}=100)\end{array}$ & $\begin{array}{c}\text { Control group } \\
(\mathbf{N}=100)\end{array}$ & \multicolumn{2}{|c|}{ Independent t-test } \\
\cline { 2 - 5 } & Mean \pm SD & Mean \pm SD & $t$ & P-value \\
\hline HB & $10.58 \pm 1.66$ & $11.41 \pm 1.55$ & -2.604 & $0.011^{* *}$ \\
\hline Total leucocytes count & $12.25 \pm 4.08$ & $7.84 \pm 2.09$ & 6.809 & $<0.001^{* *}$ \\
\hline PLT & $285.36 \pm 88.15$ & $246.64 \pm 63.58$ & 2.519 & $0.013^{*}$ \\
\hline CRP & \multicolumn{5}{|c|}{} \\
\hline - Positive [N (\%)] & $100(100 \%)$ & $0(0 \%)$ & 60.00 & $0.001^{* *}$ \\
\hline - Mean \pm SD & $38.88 \pm 31.66$ & -- & --- & --- \\
\hline
\end{tabular}

$\mathrm{N}$ : number, SD: standard deviation, HB: haemoglobin, PLT: platelet, C-RP: C- reactive protein, **: P-value is statistically highly significant

Table (5): Value of serum sodiumof the studied groups

\begin{tabular}{|l|c|c|c|c|}
\hline \multirow{2}{*}{} & $\begin{array}{c}\text { Case group } \\
(\mathbf{N}=\mathbf{1 0 0})\end{array}$ & $\begin{array}{c}\text { Control group } \\
(\mathbf{N}=\mathbf{1 0 0})\end{array}$ & \multicolumn{2}{|c|}{ Independent t-test } \\
\cline { 2 - 6 } & Mean \pm SD & Mean \pm SD & $\mathbf{t}$ & P-value \\
\hline Value of sodium & $132.08 \pm 4.18$ & $139.42 \pm 2.57$ & -10.577 & $<0.001 * *$ \\
\hline
\end{tabular}

$\mathrm{N}$ : number, SD: standard deviation, $* *$ : P-value is statistically highly significant

Table (6): Correlation between respiratory distress and value of serum sodium

\begin{tabular}{|c|c|c|c|}
\hline \multirow{2}{*}{ Respiratory distress } & Value of sodium & \multicolumn{2}{|c|}{ One way ANOVA } \\
\cline { 2 - 2 } & Mean \pm SD & F & P-value \\
\hline I & $133.32 \pm 3.40$ & & \\
\hline II & $133.05 \pm 3.61$ & \multirow{3}{*}{38.836} & \\
\hline III & $130.83 \pm 4.25$ & & \\
\hline IV & $126.30 \pm 4.10$ & & \\
\hline no RD & $139.42 \pm 2.57$ & & \\
\hline
\end{tabular}

SD: standard deviation,RD: respiratory distress, $* *$ : P-value is statistically highly significant

Table (7): Cut off value, Sensitivity, Specificity, PPV, NPV of serum sodium value of cases versus controls

\begin{tabular}{|c|c|c|c|c|c|c|}
\hline & Cut off point & AUC & Sensitivity & Specificity & PPV & NPV \\
\hline Value of sodium & $\leq 134.3$ & 0.937 & 80.00 & 100.00 & 100.0 & 83.3 \\
\hline
\end{tabular}

AUC: area under the curve, PPV: positive predictive value, NPV: negative predictive value

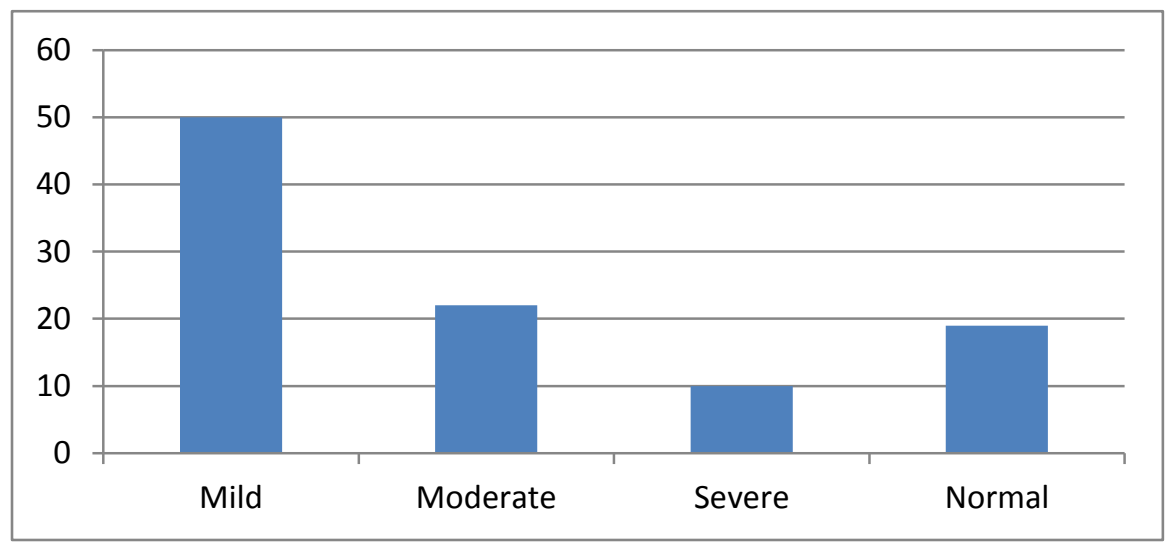

Figure (1): Serum sodium levels among case group 


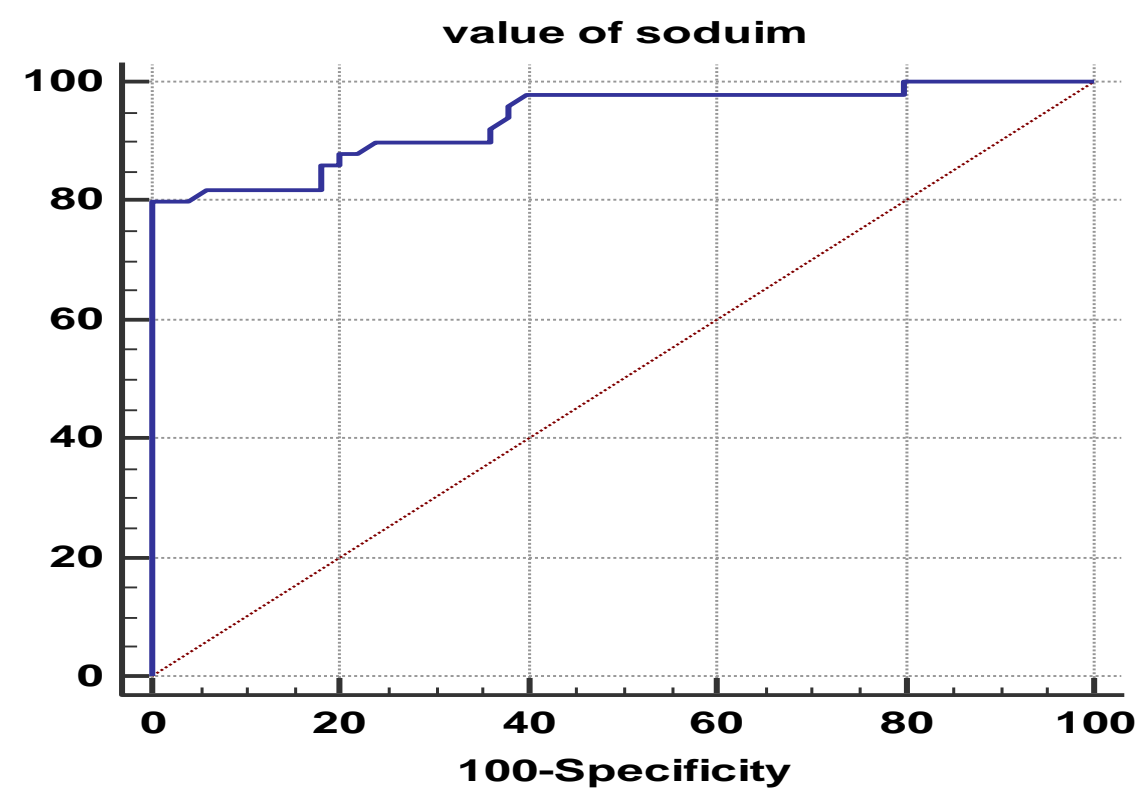

Figure (2): ROC curve analysis of sodium (cases versus controls)

\section{DISCUSSION}

Community acquired pneumonia is one in all the foremost common serious infections in kids. It accounts for about $18 \%$ of deaths per year in children fewer than 5 years of age ${ }^{(7)}$.

The WHO estimates that two-thirds of deaths due to pneumonia occur during infancy and more than $90 \%$ occur in developing countries. The explanation for the high percentage of pneumonia in developing countries includes overcrowding, malnutrition, low birth weight and limited access to health services ${ }^{(8)}$. In Egypt, it was estimated that 10\% of deaths below the age of 5 years is likely caused by pneumonia ${ }^{(9)}$.

Sodium is an electrolyte present in all body fluids and is important to traditional body function. Sodium, along with other electrolytes such as potassium, chloride, and bicarbonate, help cells function normally and regulate the amount of fluid in the body ${ }^{(10)}$. Hyponatremia is one of the most commonly diagnosed electrolyte disorders in clinical medicine. Because it is often an indicator of an underlying disease, the diagnosis of hyponatremia is important in preventing morbidity and mortality ${ }^{(11)}$.

Regarding the demographic data in our study, there was no statistically significant difference between cases and control groups as regards their age and sex. Our study revealed that $76 \%$ of cases presented with a cough which is the most frequent symptom in pneumonia. In agreement with our study, Bennet ${ }^{(12)}$ revealed that cough is the most common symptom of pneumonia in infants, along with tachypnea, retractions, and hypoxemia. These may be complained about by congestion, fever, irritability, and reduced feeding.
In our study, vital signs were significantly higher in children with pneumonia when compared to healthy controls (P value 0.001). In agreement with our study, Bradley et $\boldsymbol{\text { al }} .{ }^{(\mathbf{1 3 )}}$ reported that tachypnea seems to be the most significant clinical sign. To be measured accurately, the respiratory rate must be counted over a full minute when the child is quiet. In febrile children, the absence of tachypnea has a high negative predictive value $(97.4 \%)$ for pneumonia ${ }^{(14)}$. Conversely, the presence of tachypnea in febrile children incorporates a low positive predictive value $(20.1 \%)$. Fever alone will increase the respiratory rate by 10 breaths per minute per degree Celsius. In febrile children with tachypnea, the finding of chest retractions, grunting, nasal flaring, and crepitation increase the likelihood of pneumonia. The World Health Organization (15) uses tachypnea in the presence of cough as the diagnostic criterion of pneumonia in developing countries where chest radiography is not readily available.

In our study, CRP was significantly higher in cases than controls ( $\mathrm{P}$ value $<0.001)$ that was comparable to the study of Principi \& Espositos ${ }^{(16)}$ and Alcoba et $\boldsymbol{a l} .{ }^{(17)}$ who reported that children with high CRP values can be tested using a pneumococcal PCR to rule in the diagnosis of pneumonia with a high positive predictive value.

Our study showed that serum level of sodium was significantly decreased in the patient with pneumonia compared to healthy control (132.08 \pm 4.18 vs $139.42 \pm 2.57$ ) (P-value 0.001). Hyponatremia was present in $82 \%$ of patients with CAP.

Serum sodium had relatively high specificity which means that it could be used to exclude pneumonia. Serum sodium exhibited high sensitivity 
which means that it could be used in predicting the presence of pneumonia. ROC curve of sodium showed that area under the curve (AUC) was 0.937 and suggested that serum sodium level cut-off point for making a diagnosis of CAP was $134.3 \mathrm{mmol} / \mathrm{L}$.

In agreement with our study, Karger et al. (18) showed that serum sodium level decreased in the pneumonic patient than those of control subject and showed that hyponatremia is a common complication present at the time of admission for CAP.

Level of hypernatremia increased with increasing the degree of respiratory distress $(\mathrm{P}$-value 0.001). In agreement with our study, Karki et al. ${ }^{(19)}$ documented that hyponatremia among CAP patients at hospital admission was common and the severity of hyponatremia increased with increasing the severity of CAP. Also, Zilberberget al. ${ }^{(20)}$ documented that hyponatremia is common among hospitalized patients with CAP and associated with worsened clinical and economic outcomes.

Our study has several limitations: Firstly; relatively small sample size; secondly; cases were taken from a single center and finally; further investigation with serum and urine osmolality and urine sodium could not be done.

Our study recommended that serum sodium level, in addition to other laboratory investigations, can be used to diagnose pneumonia and its severity and mortality can be avoided by early diagnosis and proper treatment.

\section{CONCLUSIONS}

Hyponatremia is a common finding in children with CAP. The degree of hyponatremia seems to be related with the severity of pneumonia. Sodium serum level was decreased with increasing the grade of respiratory distress. Serum sodium should be strictly checked at admission and steps needed to be carried out immediately for the better prognosis of the patients.

\section{REFERENCE}

1. Harris M, Clark J, Coote N, Fletcher P, Harnden A, McKean M et al. (2011): British Thoracic Society guidelines for the management of community acquired pneumonia in children. Thorax, 66:1-23.

2. Clark JE, Hammal D, Spencer D, Hampton F (2007): Children with pneumonia: how do they present and how are they managed? Arch Dis Child., 92: 394-8.

3. Sakellaropoulou A, Hatzistilianou N, Eboriadou M, Athanasiadou- Piperopoulou F (2010): Hyponatremia in cases of children with pneumonia. Arch Med Sci.,6:57883.

4. Spasovski G, Vanholder R, Allolio B (2014): Clinical practice guideline on diagnosis and treatment of hyponatremia. Nephrol Dial Transplant.,29: 1-39.
5. Wrotek A, Jackowska T (2013): Hyponatremia in children hospitalized due to topneumonia. AdvExp Med Biol.,78:103-8.

6. Yazici S, Yazici M, Erer B, Calik Y, Ozhan H, Ataoglu S (2012): The platelet indices in patients with rheumatoid arthritis: mean platelet volume reflects disease activity. Platelets, $21: 122-5$.

7. Zar HJ, Ferkol TW (2014): The global burden of respiratory disease impact on child health. Pediatr Pulmonal., 49, 430-4.

8. Cardinal F, Cappiello AR, Mastrototaro MF, Pignatelli M, Esposito S (2013): Community acquired pneumonia in children. Early Hum Dev.,89, S49-52.

9. Morcos WM, Azmy A, Abushady MM, Moustafa HW, Ahmed A (2016): Possible etiological agents of pneumonia in Egyptian infants and children. Der pharma chemical, 8:16-21.

10. Yilmaz Y, Canda T, Kara F, Ustebay S, Aydin E, Dulger M (2016): Serum sodium levels in children with lung infections.J Pediatr Inf., 10:10

11. Singhi $S$ (2004): Hyponatremia in hospitalized critically ill children: Current Concepts. Indian J Pediatr.,71: 803-7.

12. Bennett JN (2014): Pediatric Pneumonia (workup). Medscape. Retrieved from http://emedicine.Medscape.com/article/967822.

13. Bradley JS, Byington CL, Shah SS, Alverson B, Carter ER, Harrison C et al. (2011): The management of community-acquired pneumonia in infants and children older than 3 months of age by the pediatric Infectious Diseases Society and the Infectious Disease Society of America. Clin Infect Dis., 53: 617-30.

14. Taylor JA, Beccaro MD, Don S, Winters W (1995): Establishing clinically relevant standards for tachypnea in febrile children younger than 2 years. Arch PediatrAdolesc Med.,149:283-7.

15. Swingler GH, Hussey GD, Zwarenstein M (1998): Randomized controlled trial of clinical outcome after chest radiograph in ambulatory acute lower respiratory infection in children. Lancet,351:404-8.

16. Principi N, Espositos S (2017): Biomarkers in the pediatric community acquired pneumonia. Int J Mol Sci., $18: 447$

17. Alcoba G, Keitel K, Maspoli V, Lacroix L, Manzano S, Gehri M et al. (2017): A three step diagnosis of pediatric pneumonia at the emergency department using clinical predictor, C-reactive protein and pneumococcal PCR.Eur J pediatr., 176:815-24.

18. Karger AG, Nair V, Niederman MS, Masani N, Fishbone S (2007): Hyponatremia in community acquired pneumonia. Am J Nephrol., 27:184-90.

19. Karki S, Fitzpatrick AL, Shrestha S (2015): Risk factors for pneumonia in children under 5 years in a Teaching Hospital in Nepal. Kathmandu University Medical Journal, 12:247-52.

20. Zilberberg MD, Exuzides A, Spalding J, Foreman A, Jones AG, Colby C (2008): Hyponatremia and hospital outcomes among patients with pneumonia: a retrospective cohort study. BMC pulmonary medicine, 8:16-22. 